\title{
Development of the Teacher Innovative Potential in the Conditions of Higher Education
}

\author{
Zhuravleva Yu.S. \\ Department of physical education and sports \\ RUDN University \\ Moscow, Russia \\ Kubenina73@mail.ru
}

Kodaneva L.N.

Department of physical education and sports RUDN University

Moscow, Russia

Kodaneva@mail.ru

\author{
Pastukhov I.S. \\ Department of physical education and sports \\ RUDN University \\ Moscow, Russia \\ Ivansergeev9200@mail.ru
}

\begin{abstract}
Socio-economic transformations in the country, accompanied by the search for a reasonable model of social progress and human resource management put the problem of managing the innovative potential of the teacher in the first place. At the moment, this question remains open. There is also no management model that includes not only the specifics of the interconnections of the management stages, but also the dynamics of the process personal characteristics. This article clearly defines the prospects for the formation of management theory practice and psychology, the development of the subject innovative potential in the areas of professional activity.
\end{abstract}

Keywords — innovative potential; development prospects; personality; efficiency; teacher; rational productive environment.

\section{INTRODUCTION}

Socio-economic changes in the country, accompanied by the search for a rational model of the society and human resource management dynamics put the problem of managing the innovative potential of the labour subject in the first place. The problem itself is aspectual and poorly structured, the solution of which is possible with a clear definition of some facts: human resource management, innovation potential, development of the activity potential subject.

Traditionally, human resources management is understood as a special approach to the organization and development of labour competitive subject, the achievement of which is the effectiveness of its activities. It does not contradict the goals and objectives of the organization. In our understanding, innovative potential is considered as a set of socio-cultural and creative characteristics of the individual, expressing a willingness to improve activities through innovative technologies and methods.
One of the organization functions is professional and personal development of the activity subject. At the same time, the development of the labor subject potential can be understood in two meanings. First of all, it is the activity of the subject itself, aimed at achieving competitive advantages through the implementation of the strategy and tactics of qualification characteristics, motivational and value structure transformation. Secondly, it is a process organized within the mission of the organization, supported by the means of forming a corporate culture and aimed at improving the professional development of the activity subject.

Thus, solving the problem of managing the process of innovative potential development of the labour subject, we set the following tasks:

1. The development of the professional identity competitiveness.

2. Achieving the effectiveness of the labour subject.

3. Formation of motives, goals, values of the labour subject, corresponding to the proclaimed corporate culture.

4. Development of the labour subject readiness for innovative activity, for mastering modern methods and means of achieving the set result from the psychological side.

5. Organization of optimal production environment affecting production, organizational, communicative, social, material, ethical factors.

6. Optimization of the psychological support system in the process of development of innovative potential of the subject of his professional activity.

7. Development of interpersonal and group interaction in the workforce.

We define the basic theoretical provisions, as well as the conditions for solving the tasks in the process of managing 
the development of innovative potential of the subject of activity.

I. The development of the professional identity competitiveness. Competitiveness can act both as a process and as a result of the labour subject activity. The phenomenon provides availability of such opportunities for the subject, implemented in its activities, which allow under equal conditions to achieve high results in all objective indicators of labor efficiency: quality of activity, reliability, optimality. It is important to bear in mind that the approach to the problem of reliability is based on the position that "mental properties of the person are not innate and stable. Through upbringing, education, training, you can develop the appropriate direction of the individual, the necessary willpower, interest in activities, a sense of duty, etc."[1]. It is competitiveness in this case is considered as a procedural form of mental. In this aspect, the provisions of B. G. Ananyev on the development of mental properties as the development of functional, operational, motivational mechanisms are of interest. There is no doubt that a certain degree of functional development is necessary to increase the level of operational mechanisms [10]. Based on the provisions of the author, it can be argued that an important condition for the formation of operational mechanisms of competitiveness is a high level of functional and motivational mechanisms development. "The development of abilities as the abilities of the activity subject is, first of all, due to the intellectualization of basic mental functions" [10]. Intellectualization of competitiveness is manifested in the objectivity of the perception, memory, imagination, representation functions. At the same time, the decisionmaking process, the rationality of the selected sequence of operations, the choice of necessary operations, the optimality of means to achieve the objectives of the activity are of great importance. Indicators of the professional competitiveness process developing are the quality, reliability, optimality of activities that distinguish the subject from other performers (managers) and ensure high productivity.

II. Improving the efficiency of the labour subject. Efficiency is understood as the relation of the achieved result to the maximum achievable or pre-planned result. Productivity is considered as a universal objective criterion of activity. However, there are subjective criteria for the effectiveness of activities that may act as conditions for achieving effectiveness. The following criteria can be distinguished:

1. Efficiency (the ability of the employee to perform appropriate activities at a given level of efficiency for a certain time);

2. Motivation (the presence of sustainable motives);

3. Competence (possession of the necessary knowledge, experience, skills);

4. The ability to interact (the presence of communicative competence).

5. Purposefulness (determination of the activity goals, strategy and tactics of its implementation);
6. Job satisfaction (specifics of perception of the professional environment and self-perception and expressed in relation to the employee to the work performed, to himself as a subject of labor, working conditions, etc.);

Therefore, it is necessary to take into account that when determining the conditions for managing the achievement of the subject innovative activity effectiveness, the circumstances of reflection are not only the characteristics of the production environment, but also "the activity itself, which acts as an active determinant of the subject mental activity" [6,9]. With a variety of manifestations of the "motive-goal" vector, the activity is "filled" with new forms, methods of action and relations, which will lead to a change in working capacity, value-demand sphere, the system of formation and achievement of the goal.

III. Formation of motives, goals, values of the subject of labour, corresponding to corporate culture. For this purpose, it is necessary to achieve the effect of presence, understood as "the feeling of finding a person in a certain environment" $[3,6,8]$. An ecological presence represents some degree to which the environment itself recognizes the existence of an entity and responds to it. Social presence is characterized by the presence of others providing additional evidence that the social environment exists. Undoubtedly, this leads us to the need to create a creative team, and not to limit the actions of innovation management only by regulating the functioning of one innovator. Personal presence is determined by the representation of the subject in space and time environment to achieve their goal of activity. For the subject of innovative activity it is necessary to understand the presence of existing innovative projects with significant results.

IV. Organization of the psychological support system in the process of the professional activity subject innovative potential development. In our study, we consider psychological support for the development of innovative potential of the professional activity subject as a system of measures of psychological impact, based on the diagnosis, the purpose of which is the formation of the individual reflexive abilities, the values of creativity, emotional attitude to himself as a subject of innovative activity. Psychological support, implemented on the basis of a professional's personality psychological research and his activities system of psychological diagnosis measures, counseling, correction is a prerequisite for the formation of an innovator.

V. Organization of rational productive environment. E.A. Klimov identifies the main components of the labour subject environment: social contact (socio-psychological climate, a personal example of the surrounding members of the professional community, institutions and organizations with which a person has to interact, the real place of this person in the structure of his labor community); informational (internal regulations, organization traditions, personal and public safety rules, advertising media, requirements, orders, etc.); vital (somatic) components of the subject's environment; subject (industrial, physical, chemical, biological and hygienic) [2,5]. According to N.L. Shlykova, the production environment can be considered as a system of conditions and opportunities for the existence, functioning and development 
[2] Druzhinin V.N. Experimental psychology. SPb.: Petersburg. 2002.

[3] Zavershneva E.Y. The uncertainty and complementarity principle in quantum mechanics and psychology: the problem of borrowing methodology. Bulletin MSU, Series 14, Psychology. 2001, 4, 1.

[4] Zagvyazinsky V.I., Atakhanov R. Methodology and methods of psychological and pedagogical research. M. 2001.

[5] Klimov E.A. Introduction to labor psychology: Textbook for universities. M.: Culture and sports UNITY. 1998, 350.

[6] Kozlov A.V., Budarnikov A.A., Zhuravleva Yu.S., Gonsales S.E., Lebedeva O.E. Development of the market for sports services in presentday conditions. The Journal of Social Sciences Research. 2018, S3, pp. 144-148.

[7] Kulikov L. V. Psychological research. SPb.: Speech. 2001, 184.

[8] Sergeev S. F. Presence and immersion in learning environments. SPb.: Academic project, Business book, Polytechnic University Press. 2011, 22.

[9] Shadrikov V.D. From individual to individuality: An introduction to psychology. M.: Publishing house " Institute of psychology". 2009, 112.

[10] Shlykova N. L. Psychological safety of the professional activity subject. Tver: Triad. 2003, 152.

[11] Alexsandr S. Kuznetsov. Russian Professor's meeting. Russian Journal of Physical Education and Sport. 2019, 14(1), pp. 17-22. DOI: 10.14526/2070-4798-2019-14-1-18-24

[12] Royce J.R. Powell A. Theory of personality and individual differences: factors, systems, and processes. Englewood Cliffs; London: Prentice Hall. 1983, 290. assumed that all three types are present in the organizational system, but the level of their manifestation will be different, which will certainly entail differences in the manifestation of joint innovation. At the same time, joint interaction assumes the presence of a common goal of the strategy, and the requirements for interaction are determined by the presence of subordination to the laws of the system functioning. The advantage of this type of interaction is that all members of the workforce are guided by the same principles of professional activity.

Cooperation is characterized by the presence of mutual assistance and regulation of the mutual contribution share to the overall project. In this case, there is no focus on the overall strategic goal. This type of interaction seems to be necessary in the case of differences in tactical tasks among creative groups involved in innovation.

Competition may involve the creation of obstacles to the interaction partner. In this case, the achievement of the innovative activity result is possible, but requires the inclusion of the activity subject additional resources for the protection of other entities.

Thus, the process of managing the development of the labour subject innovative potential in the conditions of higher education is a systemic phenomenon that requires the identification of relationships features between its components. Currently, this question remains open. Also, there is no management model that includes not only the specifics of the management stages relationships, but also the dynamics of this process personal factors. Thus, today the prospects of theory and practice development and psychology of the subject innovative potential development management in various spheres of professional activity are clearly defined.

\section{References}

[1] Dushkov B.A. Psychology of work, professional, information and organizational activities. M.: Academic Project: Foundation "World". 2005, 818. 